\title{
$X$. A general method for evaluating the surface- temperature of the planets; with special reference to the temperature of Mars
}

\section{Prof. Percival Lowell}

To cite this article: Prof. Percival Lowell (1907) X. A general method for evaluating the surfacetemperature of the planets; with special reference to the temperature of Mars, Philosophical Magazine Series 6, 14:79, 161-176, DOI: 10.1080/14786440709463668

To link to this article: http://dx.doi.org/10.1080/14786440709463668

曲 Published online: 16 Apr 2009.

Submit your article to this journal $[\pi$

Џll Article views: 5

Q View related articles $\longleftarrow$

Citing articles: 1 View citing articles $\square$ 
Evaluating the Surface-Temperature of the Planets.

polar coordinates and omitting as before the time-factor, we have

$$
\psi=\mathrm{A}_{0} J_{0}(k r)+\ldots+\left(\mathrm{A}_{n} \cos n \theta+\mathrm{B}_{n} \sin n \theta\right) J_{n}(k r)+\ldots,
$$

$n$ being integral.

'Thus mean $\psi$ over circle of radius $r=\mathrm{A}_{0} \mathrm{~J}_{0}(k r)$. At the centre of the circle, $\dot{\psi}_{r=0}=A_{0}$; so that mean $\psi$ over circle $r=\psi_{r=0} \times J_{0}(k r)$, and vanishes as before when $J_{0}(k r)=0$.

A similar method applies in three dimensions. Thus ('Theory of Sound,' $\$ 330$ ) we have in general

$$
\psi=-2 i k \mathrm{~s}_{0} \frac{\sin k r}{k r}+\text { terms in spherical harmonics of orders }
$$

1, 2, \&c., vanishing when integrated over a sphere and also vanishing when $r=0$. Hence

$$
\text { Mean } \psi \text { over sphere } r=\psi_{r=0} \times \frac{\sin k r}{k r} \text {. }
$$

Accordingly mean $\psi$ vanishes if $k r=n \pi$, or $r=\frac{1}{2} n \lambda$. If $k r=\left(n+\frac{1}{2}\right) \pi$,

$$
\text { Mean } \psi \text { over } r=\psi_{r=0} \times \frac{ \pm 1}{\left(n+\frac{1}{2}\right) \pi} .
$$

For an example, reference may be made to the case of plane waves treated in $\S 334$.

X. A General Method for Evaluating the Surfuce-Temperature of the Planets; with special reference to the Temperature of Mars. By Prof. Percival Lowel. *.

THE surface-temperature of the several planets is a subject of fundamental importance to an understanding of their physical conditions. To attack the problem critically is therefore of interest, the more so that it has not hitherto been done.

Heat hitherto deduced from Distance only.-For example, up to the present time the chief obstacle to crediting Mars with the possibility of life has lain in accounting for sufficient heat on the surface of the planet. Yet so far the determination of this heat has been limited to simple consideration of distance from the sun. Thus Prof. Young, who feels the difficulty acutely, says in his 'General Astronomy' (ed. 1898, p. 363), "We know that on account of the planet's distance from the Sun the intensity of solar radiation upon its surface must be less than here in the ratio of $1^{2}$ to $1.524{ }^{2}$ "; while for

* Communicated by the Author.

Phil. Mag. S. 6. Vol. 14. No. 79. July 1907. 
the resulting temperature, he seems to have assumed either with Newton that a body radiates heat in direct proportion to its temperature, which would give for the mean temperature of Mars $223^{\circ} \cdot 6$ abs. $\left(-236^{\circ} \mathrm{F}\right.$.), or Dulong and Petit's law, which would make it $363^{\circ}$ abs. or $-96^{\circ} \mathrm{F}$., for he entertains the possibility that the polar caps may be composed of solid carbonic acid, which freezes only at $-109^{\circ} \mathrm{F}$.

A closer determination has recently been made by Moulton, by taking Stefan's law of radiation, that of the fourth power of the temperature. On this basis the mean temperature comes out $-35^{\circ} \mathrm{F}$., the reasoning being this :-If a body remain at the same temperature it must radiate as much heat as it receives, and, reversely, receive as much as it radiates. Consequently the temperature is as the fourth root of the amount received. Absolute zero is minus $459^{\circ} \mathrm{F}$. The mean temperature of the Earth is usually taken at $60^{\circ} \mathrm{F}$. Therefore, to determine the mean temperature of Mars we have, calling $a$ its temperature on the absolute scale, the following equation :-

$$
x: 519^{\circ} \text { abs. : }: \sqrt[4]{4}: \sqrt[4]{9},
$$

which gives $35^{\circ} \mathrm{F}$. for the mean temperature of the planet.

Now in these and similar determinations, the only thing considered is the distance from the sun, as if the surfaces of the planets were immaterial points in space, and the whole heat arriving there went to warm the bodies. But such is far from being the fact. The actual amount of heat received is not at all what mere distance would lead one to infer, quite apart from the blanketing effect of air.

The following solution of the problem is general. After developing it we shall apply it to the Farth and Mars.

Division of Radiant Energy.-So soon as a radiant ray strikes matter it suffers division of its energy. Part of it is reflected, part absorbed, and part transmitted. What is reflected is sent off again into space, performing no work in the way of heating the body. Now the amount reflected is not the same in all cases, depending for its proportion upon the character of the matter the ray strikes.

If the surface of a planet be itself exposed unblanketed by air, the absorbed and transmitted portions go to heat the planet, directly or indirectly.

If the planet be surrounded by air, the portion transmitted by this air, plus what is radiated or reflected from it to the solid surface, must first be considered. Then upon this as a basis must secondly be determined how much the surface in 
its turn reflects. The balance alone goes to warm the ground or ocean.

Light and Heat. Albedo.-Now radiant energy is light, heat, or actinism merely according to the effect we take note of. If our eyes were sensitive equally to all wave-lengths, we could gauge the amount of heat received by a body by the amount of light it reflected, that is by its intrinsic brightness or albedo. For this percentage deducted from one hundred would leave the percentage of heat received. Though our eyes are not so sensitive this procedure may still be applied, provided account be taken of the heatdepletion suffered by the invisible rays, as well as of that undergone by the visible ones.

To solve the problem, therefore, we must find, first the ratio of the visible to the invisible rays, second the albedoes of the several planets, and thirdly the loss suffered by the rays we cannot see.

Actinometer.-Actinometers and pyrheliometers are instruments for measuring in toto the heat received from the sun; and they have been applied by Violle, Crova, Hansky, and others to the determination of this quantity at given places, and so to a conclusion as to the amount of heat outside our air, or the Solar Constant. Langley's great contribution to the subject was the pointing out that the several wave-lengths of the different rays were not of homogeneous action or modification, and that for an exact determination of the Solar Constant it is necessary to consider the action of each separately, and then to sum them together. To this end he invented his spectro-bolometer.

Bolometer.-By means of this instrument Langley mapped the solar radiation to an extension of the heat spectrum unsuspected before. He then carried it up Mt. Whitney, in California, and discovered two important facts : one that the loss in the visible part of the spectrum was much greater, not only actually but relatively to the rest, than had been supposed, and the other that the greater the altitude at which the observations were made the larger the value obtained for the solar constant. Both of these are pertinent to our present inquiry.

With a rock-salt prism instead of a glass one he next extended still farther the limits of the heat spectrum towards the red, the effect of the solar radiation proving not negligible as far as $\lambda=15 \mu$.

Very's Work.--In 1901 Prof. Very, who had been his assistant earlier, published an important memoir on the Solar Constant based upon these bolometric observations, but with M 2 
a value for it got from taking spectral curves derived from simultaneous actinometric and bolometric determinations at Camp Whitney and Lone Pine; a notable improvement, since. simultaneity alone justifies comparison. From these curves as bases he obtained one for outside the atmosphere by consideration of both air and dust effects in selectively reflecting and diffracting the energy waves. The air effect is proportionate to the air-mass, but the dust-effect increases in greater ratio as one nears the surface of the ground. The formulæ he used were adaptations of those of Rayleigh for the selective reflexion and diffraction of small particles. (U.S. Department of Agriculture, Weather Bureau, No. 254.)

Energy of Invisible and Visible Spectrum.-Beginning with his curve for outside our atmosphere, planimetric measurement of the area included between it, limiting ordinates at the side and the base-which integral gives the radiant energy received between the limits-yields the following results :-

Distribution of Heat in the Spectrum.

$\begin{array}{lcc} & \text { Wave-lengths. } & \text { Percentage. } \\ \text { Invisible } \lambda & =0.2 \mu \text { to } 0.393 \mu & 2.5 \\ \text { Visible } & =0.393 \mu, 0.76 \mu & 32 \cdot 0 \\ \text { Invisible } & =0.76 \mu \text { " } 15.0 \mu & 65.5 \\ & & \\ & & 100 \cdot 0\end{array}$

giving for the

Visible portion 32 per cent.

Invisible portion 68 per cent. of the whole.

Loss of Heat in traverse of the Air.-Turning now from the question of the initial heat for different parts of the spectrum at the time the solar radiation enters the air, we come next to consider the loss the several rays sustain in their traverse of it.

Taking Very's curves for the radiation at the confines of the atmosphere at Camp Whitney and at Lone Pine from $\lambda=0$ to $\lambda=1 \cdot 2 \mu$, and for beyond it using the absorption in the red and infra-red from the Alleghany measures which he considers the same as those of Ione Pine, we have, by planimetric measurement as before, calling the whole heat at the confines of the atmosphere unity :-

$$
\begin{aligned}
& \text { Transmission. }
\end{aligned}
$$

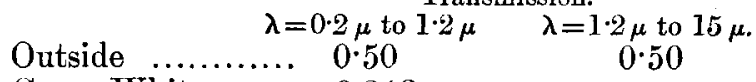

$$
\begin{aligned}
& \text { Camp Whitney ... } 0.313 \\
& \text { Lone Pine ........ } 0.243 \quad 0 \cdot 251
\end{aligned}
$$


'To get that for sea-level we shall take Crova's self-registering actinometric measures at Montpellier (height $40 \mathrm{~m}$.) made on August 13,1888, at $12^{\mathrm{h}} 30^{\mathrm{m}}$ under a barometer of $761 \mathrm{~mm}$., and with them those made simultaneously on Mt. Ventoux (height $2000 \mathrm{~m}$.). The respective calories he obtained were :-

Montpellier. Mt. Ventoux.

Calories. Bar. Calories. Bar.

Aug. $13,12^{\mathrm{h}} 30^{\mathrm{m}}, 1888 \ldots 0 \cdot 975761 \cdot 1 \mathrm{~mm}$. $1 \cdot 360613 \cdot 5 \mathrm{~mm}$.

We shall reduce these to the same scale as the Lone Pine results, made with the pyrheliometer and used by Very, which were :-

\section{Lone Pine.}

Aug. 11, 12,14: $12^{\mathrm{h}}-12^{\mathrm{h}} 30^{\mathrm{m}}, 1881.1 .533$ calories, bar. $663 \mathrm{~mm}$. giving for

Montpellier.

$1 \cdot 180$ calories.
Mt. Ventoux.

$1 \cdot 643$ calories.

This value of $1 \cdot 180$ is one which is probably about the average of clear days in our latitude, the day in question being registered by Crova as "very clear."

From these several data we find the following values for the solar radiation received at the respective posts, in calories in one column, in percentage of that entering the atmosphere in another:-

Solar Radiation.

\begin{tabular}{|c|c|c|c|}
\hline Outside the atmosphere & $\begin{array}{r}\text { Bar. } \\
0\end{array}$ & $\begin{array}{c}\text { Calories. } \\
3 \cdot 127\end{array}$ & $\begin{array}{c}\text { Percentage. } \\
1.000\end{array}$ \\
\hline Camp Whitney ........ & $500 \mathrm{~mm}$. & $1 \cdot 896$ & $0 \cdot 606$ \\
\hline Lone Pine $\ldots \ldots \ldots \ldots \ldots \ldots$ & 663 & $1 \cdot 533$ & $0 \cdot 490$ \\
\hline Montpellier ......... & 761 & $1 \cdot 180$ & $0 \cdot 377$ \\
\hline
\end{tabular}

The loss in the visible spectrum as shown by the bolometer is almost wholly from selective or general reflexion and from diffraction, that in the invisible one from selective absorption. The absorptive loss by bands in the former is only about 1 per cent. of the whole, and the loss by reflexion in the latter probably not over 7 per cent. of its depletion.

Depletion in Visible Rays.-We may now find the depletion in the visible part of the spectrum which is not in general the same as that for the invisible part, decreasing relatively with the altitude and reversely increasing as the air envelope becomes thicker. It does this at a greater rate than the increase of the air-mass because the particles suspended in 
the air, dust, water-globules, and ice, augment more rapidly than the air-mass as one approaches the ground.

Drawing the curve for transmission at the sea-level on the same principles as those for outside the atmosphere at Camp Whitney and at Lone Pine, and then measuring the amounts of transmission of each within the limits of the visual rays, from $\lambda=0.393 \mu$, the $K$ line, to $\lambda=0.76 \mu$, the $A$ band, we get the following table:-

Transmission of Solar Radiation in the Visible Spectrum.

Calories received from Visible portion the whole spectrum. transmitted.

Outside the atmosphere ..... $3 \cdot 127 \quad 1 \cdot 000$

Camp Whitney ........... $1.896 \quad 0664$

Lone Pine ............... $1.533 \quad 0.482$

Sea-level.................. $1 \cdot 180 \quad 0 \cdot 210$

The relative loss in the regions $\lambda=0.393 \mu$ to $\lambda=0.76 \mu$ and $\lambda=0.76 \mu$ to $\lambda=1.2 \mu$ between the several stations is as follows :-

Outside to Camp Whitney....... 0.10 .

Camp Whitney to Lone Pine ... $0.055 \quad 0.010$

Lone Pine to sea-level ......... $0.086 \quad 0.027$

Light received from the Day Sky.-To these transmissions must be added that part of the solar radiation which, scattered by reflexion and diffraction in the atmosphere, is reflected upon the ground cansing the brightness of the day sky : it is sufficient to obliterate the stars. Compared with direct sunlight, its amount as determined by Langley ('Professional Papers of the Signal Service,' vol. $\mathrm{xv}$.) is :

$$
\text { Illumination ........ } 80 \quad 19
$$

or 24 per cent. of the Sun's light. We must therefore increase the energy transmitted by 24 per cent. of itself. This gives finally :-

\begin{tabular}{lcccc} 
Outside $\ldots \ldots$ & \multicolumn{2}{c}{ Transmission. } & $\begin{array}{c}\text { Samie as affected } \\
\text { by the daylight. }\end{array}$ & $\begin{array}{c}\text { Portion reflected } \\
\text { into space. }\end{array}$ \\
Sea-level $\ldots \ldots$ & 0.21 & 1.00 & 0 \\
0.21 & 0.26 & 0.74
\end{tabular}

Albedo of the Earth.-Now the reflected fraction of the incident energy in the visible spectrum is that by which we see the body, and is called its albedo. The albedo of our air, then, comes out 74. To get the whole albedo of the Earth we must add to it the albedo of the surface. 
the Surface-Temperature of the Planets.

The albedo of various rocks and of the ocean is as follows:-

\begin{tabular}{|c|c|}
\hline White quartzite $\ldots \ldots \ldots \ldots \ldots \ldots \ldots$ & $0 \cdot 25$ \\
\hline Clay shale ....... & $0 \cdot 16$ \\
\hline Dark slate & 0.09 \\
\hline Ocean................ & 0.075 \\
\hline $\begin{array}{l}\text { For Forest we may perhaps take } \\
\text { and Snow according to purity... }\end{array}$ & $\begin{array}{l}0.07 \\
0.50 \text { to } 0.78\end{array}$ \\
\hline
\end{tabular}

The percentages of distribution of surface being about :-

$\begin{array}{lrr}\text { Ocean } \ldots \ldots \ldots \ldots \ldots \ldots \ldots . & 72 \\ \text { Forest ................... } & 10 \\ \text { Steppes and Desert .......... } & 10 \\ \text { Polar caps.................. }\end{array}$

We deduce $\cdot 11$ for the albedo of the surface. But this being illuminated by only 26 per cent. of the light outside the air, gives about $\cdot 03$ for its quota to the planet's illumination. Whence finally the Earth's whole albedo to one viewing it from space becomes $\cdot 74+\cdot 03=0 \cdot 77$. This is the albedo of the Earth for a clear sky.

As the Earth is about 50 per cent. cloud-covered (see the researches of Teisserinc de Bord on Nebulosity) and the albede of clond is 0.72 , we get finally for the albedo of the Earth $0 \cdot 75$.

Value of Loss of Light a minimal one.-That the value above found for the percentage transmission of solar radiation to the earth's surface is a maximal rather than a minimal amount and the albedo a minimal rather than a maximal one, is hinted by the fact that the higher the observer ascends above the surface the greater his estimate of the solar constant becomes. Thus Langley, in his memoir on the Mt. Whitney Expedition, says :-

"In accordance with the results of previous observers, then, and of our own with other instruments, we find a larger value for the Solar Constant as we deduce it from observations through a smaller air-mass." The italies are his.

Depletion by Water-vapour on Mars.-We are now in a position to estimate the heat actually received respectively at the surfaces of Mars and the Earth. The visual part of the spectrum containing 32 per cent. of the incident solar radiation gives us its quota directly from the albedo, since the heat received $=1$ - albedo. The invisible portion containing 65 per cent, of the whole depends upon the character of the air and of what it holds in suspension. The greater bulk of the depletion in this part of the spectrum comes from the absorption by water-vapour, water itself or ice and carbon 
dioxide. At the earth's surface the transmission in consequence is about $\check{0} 0$ per cent. ; at Camp Whitney it was about 59 per cent. We might, therefore, suppose it still greater through the air of Mars, which is very thin. and if we did so, we should find a still larger fraction of solar heat to be received by the planet's surface. So that such a supposition would actually increase the cogency of the present argument. But the very thinness of the air joined to the lesser gravity at the surface of the planet would lower the boiling-point of water, as investigation shows (see later in the paper) to something like $110^{\circ} \mathrm{F}$. The sublimation at lower temperatures would be correspondingly increased. Consequently the amount of water-vapour in the Martian air must on that score be relatively greater than in our own.

By Carbon Dioxide.-Carbon dioxide, because of its greater specific gravity, would also be in relatively greater amount, so far as this cause is considered. For the planet would part, cateris paribus, with its lighter gases the quickest. Whence as regards both water-vapour and carbon dioxide we have reason to think them in relatively greater quantity than in our own air at corresponding barometric pressure. Since, therefore, thinness of air and its constitution tend to offset each other, we may assume provisionally that the absorption due to both eauses is what it is with us at Camp Whitney, or about 40 per cent. of the whole, leaving 60 per cent. of the heat transmitted.

It is distinetly to be noted not only that this conservative estimate lowers the determination of the heat received at the surface of Mars, but that what is thus lost in reception goes to make the retention of the heat received all the greater.

Albedoes of Planets.- We turn now to the albedoes. The albedoes of the several planets, according to the determinations latest obtained, those by Müller at Potsdam, together with that found above for the Earth and for the Moon by Zöllner, stand thus :-

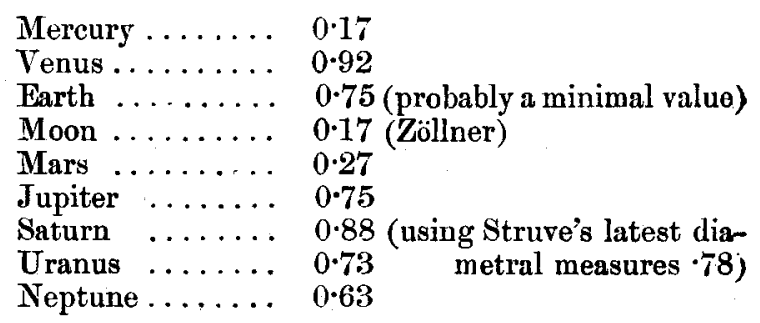

Hect receired by Earth and Mars.-With these data we sum 
up the radiant energy received from the whole spectrum for the two planets, thus :-

Heat received at the Surfaces of Mars and the Earth.

$$
\begin{aligned}
& \text { Percent. of heat received } \\
& \text { to whole energy of it } \\
& \text { whole energy. part of the spectrum. } \\
& \begin{array}{ccccc}
\text { Visual spectrum } & \ldots \ldots & 32 & \text { Mars, } & \text { EarT } \\
& & 73 & 23
\end{array} \\
& \text { Invisible }, \quad \ldots \ldots 6 \text { 65) } \\
& \text { Total } \ldots \ldots \ldots . \quad \overline{64} \quad \overline{41 \cdot 5}
\end{aligned}
$$

Insolation.-But this is not all. The above deduction applies only to such sky as is clear. Now the Earth is cloud-covered to the extent of 50 per cent. of its surface on the average, Mars, except for about six Martian weeks, at the time of the melting of the polar cap and over an area extending some fifteen degrees from the pole, stands perpetually unveiled. The surface thus fog-enveloped is 0.034 of its hemisphere and the time 0.23 per cent. of the half year, whence the total ratio of cloud to clear the whole year throngh over the whole surface is less than 1 per cent.

The albedo of cloud being 0.72 , its transmission, including absorption re-given out, cannot exceed 0.28 and may be taken at $0 \cdot 20$. Consequently the effective heat received on this score by the Earth is about as $\cdot 20 \times \cdot 50 \times \cdot 50=60$ per cent., and for Mars 99 per cent.; the ratio that of $\cdot 60$ to $\cdot 99$. This agrees with Arrhenius's estimate of the heat transmissibility of cloud.

Taking now Stefan's law that the radiation of a body is as the fourth power of its temperature, which is now generally accepted, and since its enunciation by Stefan has been deduced from theoretic considerations by both Boltzmann and Galitzine, and remembering that, since the two planets maintain their respective mean annual temperatures, they must radiate as much heat as they receive, we have the following equation from which to find the mean annual temperature of Mars, $x$, in which $459^{\circ} \cdot 4+60^{\circ}$ or $519^{\circ} \cdot 4 \mathrm{~F}$. on the absolute scale denotes the mean annual temperature of the Earth :--

$$
\begin{aligned}
& x: 519^{\circ} \cdot 4:: \sqrt[4]{1^{2} \times \cdot 64 \times \cdot 99}: \sqrt[4]{1 \cdot 524^{2} \times \cdot 415 \times \cdot 60}
\end{aligned}
$$

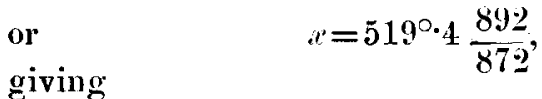

$$
\begin{aligned}
& x=5: 31^{\circ}+4 \mathrm{abs}=72 \mathrm{H} \text {. or } 22^{\circ} \mathrm{C} \text {. }
\end{aligned}
$$


Heat received and Heat retained.-Snch, then, would be the mean annual temperature of the planet, were the heat retained as well there as here. I am far from saying that such is the temperature. For the retention is not the same on the two planets, being, on account of its denser air, much better on the Earth. But that such is the amount receired is enough to suggest very different ideas as to the climatic warmth from those hitherto entertained.

Temperature deduced from Heat retained.-To obtain some idea of the heat retained and of the temperature in consequence we may proceed in this way :-

Let $y=$ the radiant energy received at the surface of the Earth.

$y_{1}=$ that similarly received on Mars.

$e=$ the relative emissivity or the coefficient of radiation from the surface of the Earth, giving the ratio of the loss in twenty-four hours to the amount received in the same time, due to factors other than the transmissibility of the air, which is separately considered.

$e_{1}=$ the like coefficient for Mars.

Clouds transmit approximately $20 \mathrm{per}$ cent. of the heat reaching them ; a clear sky at sea-level 50 per cent. Consequently as the sky is half the time cloudy, the mean transmission of its air-envelope for the Earth is 35 e. For Mars it is $\cdot 60 e_{1}$.

'To get, then, the mean temperature of the planet in degrees, $x$, from the heat retained, which is the daily mean receipt less the mean loss, we have the following equation, the mean temperature of the Earth being $519^{\circ} .4 \mathrm{~F}$. abs., $288^{\circ} .5 \mathrm{C}$. above absolute zero.

$$
\frac{x}{288 \cdot 5}=\frac{\sqrt[4]{y_{1}\left(1-\cdot 60 e_{1}\right)}}{\sqrt[4]{y(1-\cdot 35 e)}}
$$

where the first term under the brackets denotes the daily receipt, the second the nightly loss.

Determination of .- To find $e$ we have the data that the fall in temperature toward morning on the Farth under a clear night sky is about $18^{\circ} \mathrm{F}$. or $10^{\circ} \mathrm{C}$., under a cloudy one about $7^{\circ} \mathrm{F}$. or $4^{\circ} \mathrm{C}$. Taking the average day-temperature from these data at $292^{\circ}$ abs. on the centigrade scale or $19^{\circ} \mathrm{C}$., and considering that for an average day sky and a clear night the transmission or loss is

$$
\frac{1}{2}(\cdot 35+\cdot 50) \text { e or } \cdot 425 e \text {; }
$$

while for an average day and a cloudy night it is

$$
\frac{1}{2}(\cdot 35+\cdot 20) e \text { or } \cdot 275 e \text {; }
$$


we form the following equation to determine $e$ :-

whence

$$
\frac{292^{\circ}-10^{\circ}}{2 y 2^{\circ}-4^{\circ}}=\frac{\sqrt[4]{y(1-.425 e)}}{\sqrt[4]{y(1-.275 e)}}
$$

Since the radiation by day is greater by about 1.15 than by night, being as $\frac{292^{4}}{282^{4}}$ we have more approximately

$$
\begin{aligned}
& \frac{1}{2}(\cdot 40+\cdot 50) e \text { or } \cdot 45 e, \\
& \frac{1}{2}(\cdot 40+\cdot 20) e \text { or } \cdot 30 e,
\end{aligned}
$$

for a cloudy night under the same conditions.

This gives

$$
e=4634
$$

or substantially what it was before. It changes the final result for the mean temperature of Mars by less than twotenths of a degree.

Determination of $\mathrm{e}_{1}$. - Since in the mean the planet radiates as much heat as it receives and

$$
y^{y}=1 \cdot 10
$$

the radiation must be in the same ratio. Whence the loss from radiation in twenty-four hours on Mars, so far as it depends on the heat received, is

$$
\begin{aligned}
e_{1} & =1.1 e \\
& =.51 .
\end{aligned}
$$

or, by the more approximate calculation in the paragraph above, it still

$$
=\cdot 51 \text {. }
$$

Substituting these values in our equation above, we find $x$, the mean temperature of Mars, $=8^{\circ} .7 \mathrm{C}$., or $=47^{\circ} .7 \mathrm{~F}$., taking into account the heat radiated away as well as the heat received, and gauging the temperature by the heat retained; by the net, instead of the gross, amount of the energy received *'.

* If we adopt Arrhenius's formula for the temperature T of the Earth's surface as affected by i1s air-envelope, we have, as determined in his paper on the effect of carbon dioxide in the air,

$$
\mathrm{T}^{\mathrm{H}}=\frac{\alpha 1+\mathrm{M}+(1-\alpha) \mathrm{A}(1+\nu)+\mathrm{N}\left(1+\frac{1}{\nu}\right)}{\gamma(1+\nu-\beta \nu)},
$$

where $\alpha=$ atmospheric absorption for solar heat,

$$
\begin{aligned}
& \beta=\quad " \quad \text { Earth-surface heat, } \\
& { }_{A}=\text { solar constant, less loss by selective reflexion by the air, } \\
& \mathrm{M}=\text { heat conveyed to the air from other points, } \\
& \mathrm{N}= \\
& \nu=1-\text { albedo of the surface } \\
& \gamma=\text { radiation constant. }
\end{aligned}
$$


If we assume clouds to transmit less heat than 20 per cent. we diminish $y$ and increase $(1-\cdot 35 e)$, so that the ultimate result is not greatly altered.

Albedo and Air.-Some interesting conclusions follow on the investigation of planetary albedo. If we classify the various planets according to their atmospheric envelopes, we

The values for these quantities found bolometrically for a clear sky are :-

$$
\begin{aligned}
& \alpha=\cdot 50, \\
& \Lambda=1-79 \times \cdot 32=\cdot 747=\text { whole spectrum - albedo of the air into } \\
& \beta=\text { approximately } \alpha \text {. visible portion, } \\
& \nu=1-\cdot 11=\cdot 89 \text {. }
\end{aligned}
$$

For the Earth in its entirety $M=0$ and $N=0$, since what is lost by convection in one place is gained in another.

Applying this same formula to the case of Mars, we have similarly :$*_{1}=\cdot 40$ approx.

$$
\begin{aligned}
A_{1} & =\frac{1^{2}}{1 \cdot 524^{2}}(1-\cdot 17 \times \cdot 32)=\text { whole spectrum } \frac{\text { albedo of its air }}{\text { into vigible portion }} \\
& =\frac{.946}{1 \cdot 524^{2}} \\
\beta_{1} & =\alpha_{1} \text { approx. } \\
\nu_{1} & =1-\cdot 13=87 .
\end{aligned}
$$

Whence for the Earth under a clear sky

$$
\mathrm{T}^{\prime}=\frac{A(1+\nu-\nu \propto)}{\gamma(1+\nu-\beta \nu)}
$$

and similarly for Mars, substituting its values for $A, \alpha$ and $\beta$. Since in both $\alpha=\beta$ and $\gamma_{1}=\gamma$ approx., we have $T_{1}$ for Mars, which gives

$$
\mathbf{T}_{1}^{\mathbf{T}^{4}}=\frac{\mathbf{A}_{1}}{\mathbf{A}} \text {. }
$$

But the Earth is 50 cloud-covered and the transmission of cloud being not more than 20 (the value he takes), we bave finally

whence

$$
\frac{T_{1}{ }^{4}}{T^{4}}=\frac{A_{1} \cdot 99}{A^{2} \cdot 60}
$$

$$
\mathrm{T}_{\mathrm{l}}=\cdot 974 \mathrm{~T} \text {, }
$$

and $T$ being $519^{\circ} .4$ abs. on the Fahrenheit scale,

$$
\mathrm{T}=505^{\circ} \cdot 7 \text {, that is } 46^{\circ} \cdot 3 \mathrm{~F} \text {. or } 8^{\circ} \mathrm{C} \text {, }
$$

a result substantially the same as we have deduced.

Had we assumed $\beta$ to be 70 and to be in the like proportion to $\alpha$ for Mars, we should have had

and

$$
\begin{aligned}
& \mathrm{T}^{4}=1 \cdot 140 \frac{\mathrm{A}}{\gamma^{\prime}}, \\
& \mathrm{T}_{\mathrm{t}}{ }^{4}=1 \cdot 10 \mathrm{I} \frac{\mathrm{A}_{1}}{\gamma_{1}},
\end{aligned}
$$

which gives not far from what we had before, since it lowers the resulting temperature for Mars by only about $4^{\circ} \mathrm{F}$. or $2^{\circ} \mathrm{C}$. 
shall discover a significance in their several albedoes. Three classes stand forth distinct:-(1) those possessing no air ; (2) those with air, but wholly or in part cloudless ; (3) those with a cloud-covering. Into these classes the planets fall in the manner below, while the albedoes they respectively present are placed alongside of them.

I. Airless bodies.

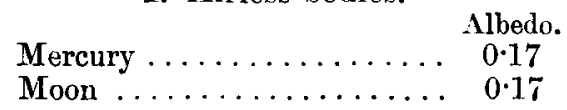

II. Air-enveloped bodies.

$\begin{array}{ll}\text { Venus, clondless, }\{\text { medium } & 0.92 \\ \text { Earth, } 50 \% \text { clouded }\} \text { air } & 0.75 \\ \text { Mars, cloudless, thin air . . . . . } & 0.27\end{array}$

III. Cloud-canopied bodies.

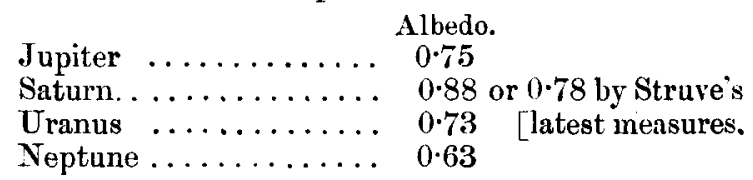

The albedu of clond is 0.72 . Whence it is clear that cloud cannot account for the albedo of Venus; but that it accords with the albedo of the four major planets. That an airenvelope increases the albedo of a planet is witnessed, first, by the greater brilliancy per unit of disk of the Earth, Venus, and Mars as compared with the airless bodies, Mercury and the Moon; and, secondly, by the relative specific brightness of Venus and Mars, together with what has above been found as to that of the Earth. It appears that the denser the air surrounding the planet, the more dazzling the aspect the planet presents. This is undoubtedly due not to the gases themselves, but to the solid or liquid particles the gases support in the shape of dust, ice-particles, or drops of water.

This testimony of the albedo that Venus is not cloudcovered but atmosphere-hid is corroborative of the observations made by the writer at Flagstaff in 1896 and at Mexico in 1897 , from which it appeared that the planet's markings were not obscured by cloud but seen as it were through a veil, and which also showed the correctness of Schiaparelli's deduction that Venus, in all probability, turned in perpetuity the same face to the Sun. That she did so was evident from the longcontinued observations at Flagstaff' and Mexico. Now such a facing always of one hemisphere sunward would cause convection-currents upward in the centre of the disk, and an 
indraught along its edge, together with an absence of moisture on the sunlit half of the planet. Dry winds of the sort blowing over a perpetual sahara must be laden with dust, which Very's investigation finds to be the chief cause of reflexion in our own air. The high albedo of Venus thus stands accounted for.

Light round Venus.-A sidelight bearing on the albedo of air comes from the prolongation of the crescent of Venus when the planet passes in inferior conjunction before the Sun.

It used to be thought that the fine circlet of light that then crowns the disk was due to refraction in the Venusian air. But in 1898 Russell at Princeton showed that it is rather reflexion from that air than refraction through it which reaches our eyes. Now that such should be the case follows from the planet's albedo, if that albedo be of atmospheric and not of nubial origin. This supports the conclusion reached by the visual observations of Venus at Flagstaff. For refraction means transmission, and if the air of Venus reflects 90 per cent. of the incident light it can refract but 10 per cent. at most. The light from it, therefore, must be reflected not refracted light in the proportion of 9 to 1 . The albedo, Russell's observations, and the Flagstaff results, thus all concur to the conclusion that Venus is not enveloped in clond.

Deduction as to amount of Martian Air-Another outcome of the consideration of albedoes is a means it gives us of approximating to the density of the Martian air. Mars' surface is chiefly Saharan, and dust, therefore, must be largely present in its air. Now from the albedo of various rocks, of forests, and of other superficies we may calculate the relative quotas in the whole albedo of Mars of its surface and its air. Five-eighths of its surface is desert and therefore of an albedo of about $0 \cdot 16$, as its hue shows: three-eighths of a blue-green, the colour of vegetation with an albedo of about 0.07 ; while one-sixth is more or less permanently white, the white of the polar caps. These would combine to give it an albedo of $0 \cdot 13$. This, however, is illuminated by so much of the light as penetrates the atmosphere only, about three-quarters of the whole. Whence the apparent albedo of the surface must be about $0 \cdot 10$. As the total albedo of the planet is $0 \cdot 27$, the remaining 0.17 is the albedo of its air.

Taking the density of the air as proportionate to its brilliancy, which would seem to be something like the fact, since the denser the air the more dust it wonld buoy up, we have for the Martian air a density about $2 / 9$ our own over each square unit of surface. 
the Surface-Temperature of the Planets.

Now if the original mass of air on each planet was as its own mass, we should have for the ratio between the Earth and Mars, $9 \cdot 3$ of atmosphere on the former to 1 on the latter. This being distributed as their surfaces, which are in the proportion of 7919 to $42 \% 0$, must be divided by 3.5 , giving $2 \cdot 7$ times as much air for the Earth per. unit of surface. The difference between $2 \cdot 7$ and $4 \cdot 6$ thus found may perhaps be attribated to the lows of air Mars has since sutfered on the supposition of proportionate masses to start with.

Air-density at surfuce of Mars.-To get the relative density of the air at the surfaces of the two planets, these amounts must be divided by the ratio of gravity at the surfaces of the two, that is by $38 / 100$.

For the density being proportional to its own increase, if $D$ denote the density at any point, we have

$$
l \mathrm{D}=-\mathrm{D} g d l t,
$$

where $g$ denotes the force of gravity at the surface of the Earth and $a$ is reckoned from that surface outward into space, whence

$$
\mathrm{D}=\mathrm{A} e^{-g \cdot x}
$$

A being the density at the surface of the planet.

For Mars we have correspondingly

$$
\mathrm{D}_{1}=\mathrm{A}_{1} e^{-g_{1} x} .
$$

For the whole mass of air over a space $d y d z$ we have, for the Earth,

$$
\int_{0}^{\infty} \mathrm{D} d x=-\underset{y}{-e^{-g x}=\infty}=\frac{\mathrm{A}}{g} .
$$

Similarly for Mars it is

$$
\frac{\mathrm{A}_{1}}{g_{1}}
$$

and as the whole mass of the Earth's atmosphere over any space $d y d z=4 \cdot 6$ that of Mars at a similar point and $g_{1}=\cdot 38 g$, we have

$$
\frac{\mathrm{A}}{1}=4 \cdot 6 \cdot \frac{\mathrm{A}_{1}}{\cdot 38} ;
$$

whence, as $\mathrm{A}=30$ inches of barometric pressture, $\mathrm{A}_{1}=2 \cdot 5$ inches.

Boiling-point on Mars.-Owing to the less amount of the Martian air and the smaller gravity at the surface of the planet, the boiling-point of water is greatly reduced, being probably in the neighbourhood of one hundred and eleven 


\section{Prof. A. Stanley Mackenzie on Secondary Radiation}

degrees Fahrenheit. If the whole mass of air be $\frac{1}{4 \cdot 6}$ of the Earth's, while gravity is $\cdot 38$ of ours, the pressure is

$$
\mathrm{M}_{1} g_{1}=\cdot 09 \text { of the Earth's, }
$$

whence the boiling-point is $44^{\circ} \mathrm{C}$ or $79+32=111^{\circ} \mathrm{F}$.

For the same reason, sublimation takes place more freely at identical temperatures there. Proportionally, therefore, there would be more water-vapour in the air.

Results,-In conclusion we may summarize the results for the more probable values of the following quantities for Mars :-

Mean temperature ......... $48^{\circ} \mathrm{F}$ or $9^{\circ} \mathrm{C}$.

Boiling-point of water $\ldots \ldots \ldots 111^{\circ} \mathrm{F}$. or $44^{\circ} \mathrm{C}$.

Amount of air per unit surface. . 7 in. or $177 \mathrm{~mm}$; $2 / 9$ of the Earth's. Density of air at surface ..... 2.5 in. or $63 \mathrm{~mm} . ; 1 / 12$ "

The look of the surface entirely corroborates the temperature results of this investigation.

XI. Secondary Radiation from a Plate exposed to Rays from Radium. By A. Stanley Mackenzie, Ph.D., Munro Professor of Physics, Dulhousie University, Halifax, N.S. *

TTHE following experiments were made to examine more 1 carefully than has been done the secondary radiation from the back side of a plate bombarded by the rays from radium, and to see what light a comparison of this radiation with that from the front side would throw on the mechanism involved in the production of secondary rays ; and, further, to see what evidence it would give of the secondary radiation of penetrating type, of which other experiments seem to show the existence.

In order to restrict to a definite bundle the beam of radium rays employed, and to shield as far as possible the rest of the apparatus from rays leaving the radium in other directions, the radium was put at the apex of a conical opening of $19^{\circ}$ half-angle in a massive block of lead. The accompanying diagram (fig. 1) will make the arrangement clear. A hole was bored through the lead block along the axis of the cone, and the radium ( $5 \mathrm{mg}$. in a glass tube) was put in its place by being inserted in the end of a brass rod which fitted the hole. The lead block had a circular cross-section of $10.7 \mathrm{~cm}$. diameter, and its greatest length was $16 \mathrm{~cm}$. As the radium was inserted to a depth of $7.7 \mathrm{~cm}$. in the block, no rays could emerge from it without passing through at least $5 \mathrm{~cm}$. of

* Communicated by the Author. 